\title{
Colorectal cancer promoter methylation alteration affects the expression of glutamate ionotropic receptor AMPA type subunit 4 alternative isoforms potentially relevant in colon tissue
}

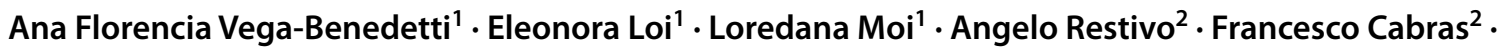 \\ Simona Deidda ${ }^{2} \cdot$ Andrea Pretta $^{3} \cdot$ Pina Ziranu $^{3} \cdot$ Sandra Orrù $^{4} \cdot$ Mario Scartozzi $^{3} \cdot$ Luigi Zorcolo $^{2}$. \\ Patrizia Zavattari ${ }^{1}$ iD
}

Received: 24 August 2021 / Accepted: 23 October 2021 / Published online: 30 October 2021

(c) The Author(s) 2021

\begin{abstract}
DNA methylation alterations are early events during tumourigenesis, affecting genes involved in the crosstalk between cells and surroundings in colorectal cancer (CRC). Among these genes, GRIA4, Glutamate Ionotropic Receptor AMPA Type Subunit 4, displays hypermethylation in the promoter region, and is an early diagnostic biomarker. It is well known that methylation can also affect alternative transcription. The purpose of this study is to evaluate the expression, at transcript and protein level, of GRIA4 main isoforms (the canonical one and a short variant) in 23 CRC and matched normal samples, of which we previously verified the methylation status. We further predicted miRNA/transcript target interactions as a possible post-transcriptional regulation using bioinformatics tools. As expected, downregulation of both variants has been observed in tumours. Interestingly, in contrast to what observed at transcriptional level, the GluR4 protein short isoform displayed higher expression than the canonical one either in normal or tumoural tissues. This may be explained by miRNA specifically targeting the canonical isoform. Our study is the first one that shows the expression of both isoforms in colon tissues. To note, the evident expression of the short isoform suggests a functional role in intestinal cell biology.
\end{abstract}

Keywords Colorectal cancer (CRC) · DNA methylation alterations $\cdot$ GRIA4 $\cdot$ Gene expression $\cdot$ Gene regulation

Ana Florencia Vega-Benedetti and Eleonora Loi are co-first authors.

Patrizia Zavattari

pzavattari@unica.it

Ana Florencia Vega-Benedetti

anaf.vegab@unica.it

Eleonora Loi

eleonora.loi@unica.it

Loredana Moi

lorymoi@gmail.com

Angelo Restivo

arestivo@unica.it

Francesco Cabras

fracab@gmail.com

Simona Deidda

simona.deidda86@unica.it

Andrea Pretta

an.pretta@gmail.com

Pina Ziranu

pziranu@libero.it
Sandra Orrù

orrusandra14@gmail.com

Mario Scartozzi

marioscartozzi@unica.it

Luigi Zorcolo

lzorcolo@aoucagliari.it

1 Department of Biomedical Sciences, Unit of Biology and Genetics, University of Cagliari, Cittadella Universitaria di Monserrato, Cagliari, Italy

2 Department of Surgery, Colorectal Surgery Center, University of Cagliari, Cagliari, Italy

3 Department of Medical Oncology, University Hospital of Cagliari, Cagliari, Italy

4 Department of Pathology, "A. Businco" Oncologic Hospital, ASL Cagliari, Cagliari, Italy 


\section{Introduction}

Cancer cells are characterized by massive changes in gene expression profile in terms of transcripts levels and expression of alternative isoforms, due to different biological mechanisms, among which alterations in DNA methylation patterns have a pivotal role [1-8].

DNA methylation at cytosines predominantly occurs in $\mathrm{CpG}$ dinucleotides known as $\mathrm{CpG}$ sites. Regions with high density of $\mathrm{CpG}$ sites, defined as $\mathrm{CpG}$ islands (CGIs), may overlap with transcription start sites. Alterations in DNA methylation pattern maintenance or de novo DNA methylation events can be associated with pathologies development. In particular, DNA methylation dramatically changes in cancer cells, i.e. a wide loss of DNA methylation occurs, whereas promoter-associated CGIs, usually un-methylated, undergo de novo methylation [4]. These aberrations, which can be cancer-specific, are considered early and frequent events in tumourigenesis, sometimes detected in premalignant tissues, becoming promising diagnostic biomarkers [9]. Promoter hypermethylation is frequently associated with gene silencing and can also affect the expression of alternative transcripts [6, 10]. Furthermore, DNA methylation alterations can be traced in cell-free circulating tumour DNA through non-invasive techniques $[1,3,11,12]$.

Other epigenetic alterations frequently found in tumours regard the post-transcriptional regulation. It has been reported abnormal expression of micro RNAs (miRNAs) that bind to target mRNAs blocking their translation and long non coding RNAs (lncRNAs) known as miRNAs sponges which antagonize miRNAs function [12-14].

In a genome-wide methylation study, we identified 74 CGIs significantly aberrantly methylated shared between colorectal cancer (CRC) and adenoma samples. Most of the genes associated with these altered CGIs encode for proteins essential for the interaction among cells and with their surrounding environment [1]. We evaluated the expression levels, using qRT-PCR and Western blot, of selected genes, barely expressed in normal colon, whose promoter CGIs were hypermethylated in CRC and we detected their further downregulation in tumour samples $[1,3]$. Among these alterations, the CGI associated with GRIA4 (Glutamate Ionotropic Receptor AMPA Type Subunit 4) gene reached very high methylation levels in tumour samples compared with normal ones and it has been shown as an excellent putative biomarker but also potentially functionally involved in CRC. This altered CGI is located in the promoter region of GRIA4, which encodes for two isoforms recognized by the same antibody, whose expression may be potentially affected by this alteration. Only the expression of the canonical isoform was evaluated in tumour and normal samples in our previous study [3]. GRIA4 encodes a subunit of the AMPA tetrameric receptor complex. Each subunit consists of the extracellular amino-terminal domain, the extracellular ligand-binding domain, three transmembrane helixes plus a membrane re-entrant loop, and an intracellular carboxylterminal domain [15]. The principal function of this receptor type, as a cationic ion channel, is mainly performed in the central nervous system, e.g. synaptic communication [16]. GRIA4 is included within the genes encoding for proteins that are involved in cell signalling and cross-talking, pathways frequently altered in cancer. Several transcript variants of GRIA4 have been identified and annotated in Ensembl Genome browser (GRCh38.p13) (https://www. ensembl.org), including 11 protein coding transcripts of which two (ENST00000282499 and ENST00000393125) have both HAVANA and Ensembl gene annotation. Indeed, two protein isoforms have been described by the NIH full-length cDNA project, whereas other five potential ones have been computationally mapped [17] (https:// uniprot.org). Regarding the first two isoforms, the shorter one consists of 433 amino acids but its function is not elucidated, whereas the longer isoform, 902 amino acidslength, is considered the canonical one. Interestingly, the structure of the shorter protein only comprises the extracellular domain of the receptor and it also differs from the canonical isoform in ten amino acids located at the C-terminal sequence.

Given the potential different functional roles of these isoforms in CRC, this work aims to investigate the expression of both isoforms at mRNA and protein levels, in tumoural and normal colon tissues.

\section{Materials and methods}

\section{Tissue samples}

The investigation cohort consisted of $23 \mathrm{CRC}$ and their matched normal tissue samples collected from the Department of General Surgery of the University of Cagliari (Italy). Normal samples were taken at a distance $>10 \mathrm{~cm}$ from the neoplastic tissue. Clinical data are presented in Table 1.

\section{DNA methylation analysis}

Genomic DNA was extracted from tumoural and matched non-tumoural tissues using the DNeasy Blood \& Tissue Kit (Qiagen, Hilden, Germany). DNA quantity of all samples was evaluated by spectrophotometric reading.

DNA samples were bisulfite converted using EZ DNA Methylation Gold Kit (Zymo Research, Irvine, CA, USA) following the manufacturer's instructions. 


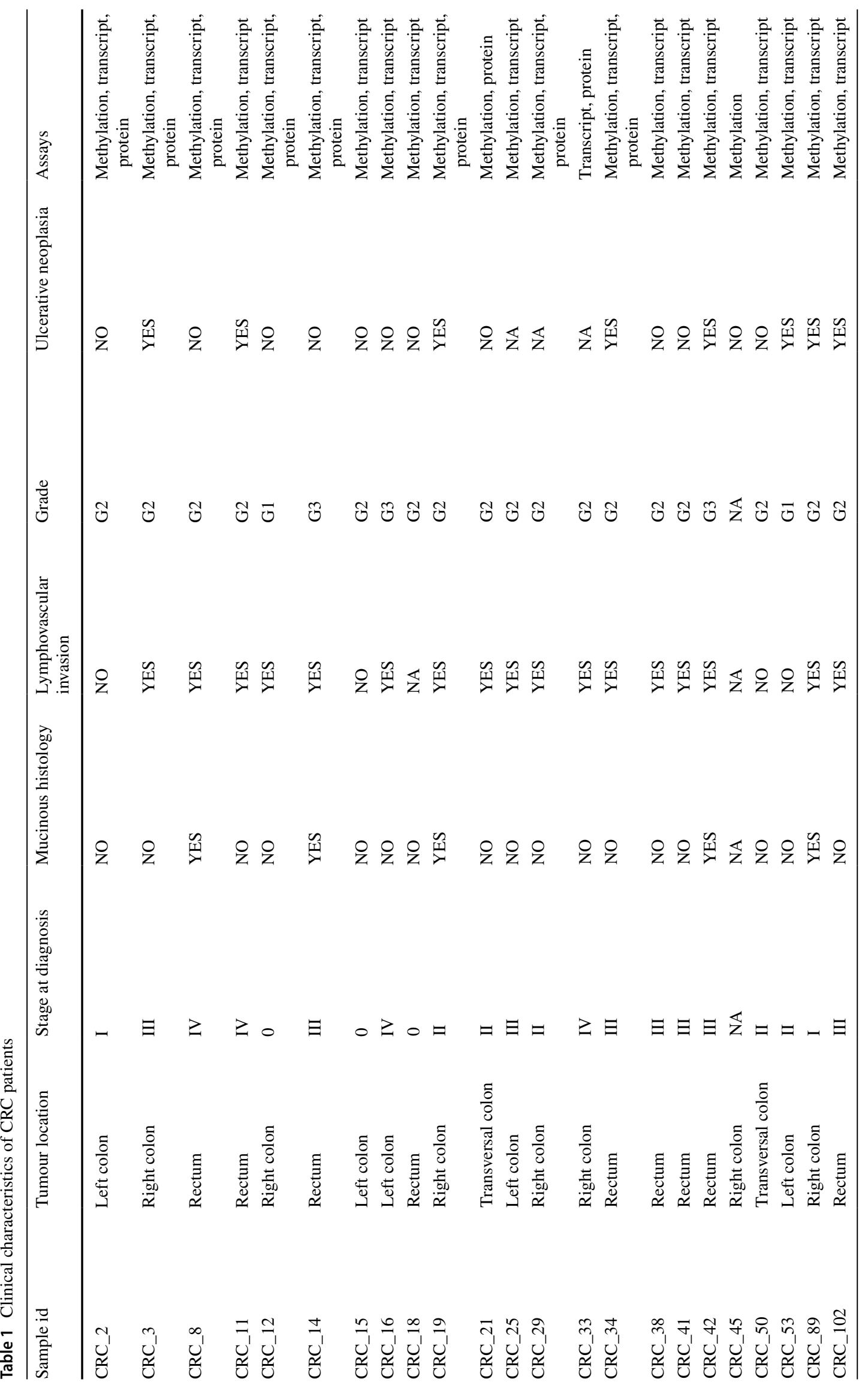


Table 2 Primers and probes sequences for MethyLight assay

\begin{tabular}{llll}
\hline Target & Forward primer $\left(5^{\prime}-3^{\prime}\right)$ & Reverse primer $\left(5^{\prime}-3^{\prime}\right)$ & Probe $\left(5^{\prime}-3^{\prime}\right)$ \\
\hline GRIA4 & GGGTTGGTGTAGGTTTGTT & CTCCCCCCTTACTTT & AACGCCGCGACCGCCACAC \\
& & CTCACATACACA & \\
& & CAA & \\
ALU-C4 & GGTTAGGTATAGTGGTTTATA & ATTAACTAAACT & CCTACCTTAACCTCCC \\
& TTTGTAATTTAGAT & AATCTTAAACTC & \\
& & CTAACCTCA & \\
\hline
\end{tabular}

GRIA4 methylation analysis was performed by MethyLight qPCR as previously described in [3]. The methylation independent control reaction (ALU-C4) was used to normalize the quantity of DNA input [18]. The reaction contained: $1 \times$ TaqMan Genotyping Master mix (Applied Biosystems, Foster City, CA, USA), $900 \mathrm{nM}$ of each primer, $250 \mathrm{nM}$ of probe, $50 \mathrm{ng}$ bisulfite converted DNA in a final volume of $30 \mu \mathrm{l}$. Primers and probes sequences are reported in Table 2. Every reaction was performed in triplicate and the experiment was conducted on a DNA Engine Opticon 2 Real-Time Cycler (Bio-Rad, Hercules, CA, USA) using the following thermal conditions: initial PCR activation step at $95^{\circ} \mathrm{C}$ for $10 \mathrm{~min}(\mathrm{~min})$, followed by 50 cycles of denaturation step at $95{ }^{\circ} \mathrm{C}$ for $15 \mathrm{~s}(\mathrm{sec})$ and annealing/extension step at $60{ }^{\circ} \mathrm{C}$ for 1 min. GRIA4 methylation levels were quantified using the $\Delta \Delta \mathrm{Ct}$ method [19]. $\Delta \mathrm{Ct}$ was calculated as the difference between $\mathrm{Ct}$ of the target assay and $\mathrm{Ct}$ of the $A L U-C 4$ control. Average $\Delta \mathrm{Cts}$ were calculated for tumoural and normal samples. $\Delta \Delta \mathrm{Ct}$ was calculated as the difference between the average tumour $\Delta \mathrm{Ct}$ and the average normal $\Delta \mathrm{Ct}$. Samples showing $\mathrm{Ct}$ values higher than 45 were excluded.

\section{mRNA expression analysis}

Total RNA was extracted from tumoural and normal samples using the RNeasy Mini Kit (Qiagen, Hilden, Germany) following manufacturer's instructions. Reverse transcription of $1 \mu \mathrm{g}$ of RNA to cDNA was performed using the High Capacity Kit (Applied Biosystems, Carlsbad, CA, USA). Gene expression was evaluated by qPCR using SsoAdvanced Universal SYBR ${ }^{\circledR}$ Green Supermix (Bio-Rad, Hercules, CA, USA). Primer sequences of GRIA4 transcript variants, ENST00000282499 and ENST00000393125 defined as long and short respectively, and of the endogenous gene TFRC are reported in Table 3. PCR conditions were as follow: first step of denaturation at $95^{\circ} \mathrm{C}$ for $2 \mathrm{~min}$, followed by 50 cycles of denaturation at $95^{\circ} \mathrm{C}$ for $15 \mathrm{~s}$ and annealing and extension at $60^{\circ} \mathrm{C}$ for $1 \mathrm{~min}$.

The transcript levels were quantified using the $\Delta \Delta \mathrm{Ct}$ method [19]. Samples showing $\mathrm{Ct}$ values higher than 45 were excluded.
Table 3 Primers for qRT-PCR expression assay

\begin{tabular}{lll}
\hline Gene & Forward primer $\left(5^{\prime}-3^{\prime}\right)$ & Reverse primer $\left(5-3^{\prime}\right)$ \\
\hline GRIA4 long & CAAAGGCTATGGAGTAGCAACG & AGCTTGTCTAAGACGCCTGC \\
GRIA4 short & GATTCAAGATGTACCAACTCTTGGC & AAAATAGGATTCTTCATCAGAGGCA \\
TFRC & GGCACAGCTCTCCTATTGAAAC & CAAAGTCTCCAGCACTCCAACT \\
\hline
\end{tabular}

\section{GluR4}

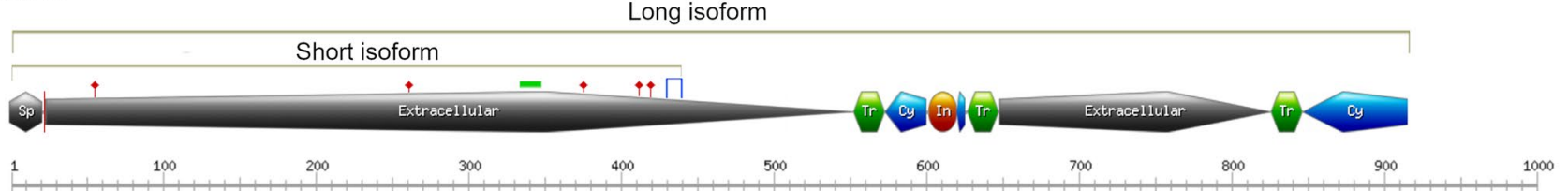

$\begin{array}{ll}\text { Sp Signal peptide } & \text { i Glycosylation sites } \\ \text { Tr Transmembrane } & \text { ПESPYVMYKKN } \rightarrow \text { PLMKNPILRN } \\ \text { cy Cytoplasmic } & - \text { Immunogen } \\ \text { In Intramembrane } & \end{array}$

Fig. 1 GluR4 protein isoforms and protein domains (green dash indicates the immunogen) 


\section{Protein expression analysis}

The protein expression levels of the long canonical and short GluR4 isoforms were studied by Western blot in a subgroup of ten matched tumour and normal tissues. Proteins from colon tissues were extracted using the Membrane Protein Extraction Kit (Mem-PERTM Plus, Thermo Fisher Scientific, Waltham, MA, USA) following the manufacturer's protocol. Protein lysate separation was performed onto a $10 \%$ SDS-polyacrylamide gel at $100 \mathrm{~V}$ for $90 \mathrm{~min}$. Then, protein transfer was done using $0.45 \mu \mathrm{m}$ nitrocellulose membrane for $90 \mathrm{~min}$. Afterwards, blots were blocked in 5\% milk overnight at $4{ }^{\circ} \mathrm{C}$ and then incubated $2 \mathrm{~h}$ with primary antibody GluR4 (0.5 $\mu \mathrm{g} / \mathrm{mL}$, PA5-18931, Thermo Fisher Scientific, Waltham, MA, USA) and NaK ATPase (1:40,000, Ab76020,
Abcam, Cambridge, UK) as gel-loading control. Once the hybridization time finished, the membrane was washed three times with Tris-buffer containing Tween-20, incubated with horseradish peroxidase-labelled secondary antibody (Jackson ImmunoResearch, Ely, UK) during $1 \mathrm{~h}$ at room temperature and washed again three times. Chemiluminescence was detected with ECL Chemiluminescent Western blotting reagents (Bio-Rad, Hercules, CA, USA). The intensity of Western blot signals was quantified using ImageJ programme and normalized respect to NaK ATPase. In Fig. 1 GluR4 protein isoforms and protein domains are illustrated, including the immunogen recognized by the antibody.

\section{GRIA4}

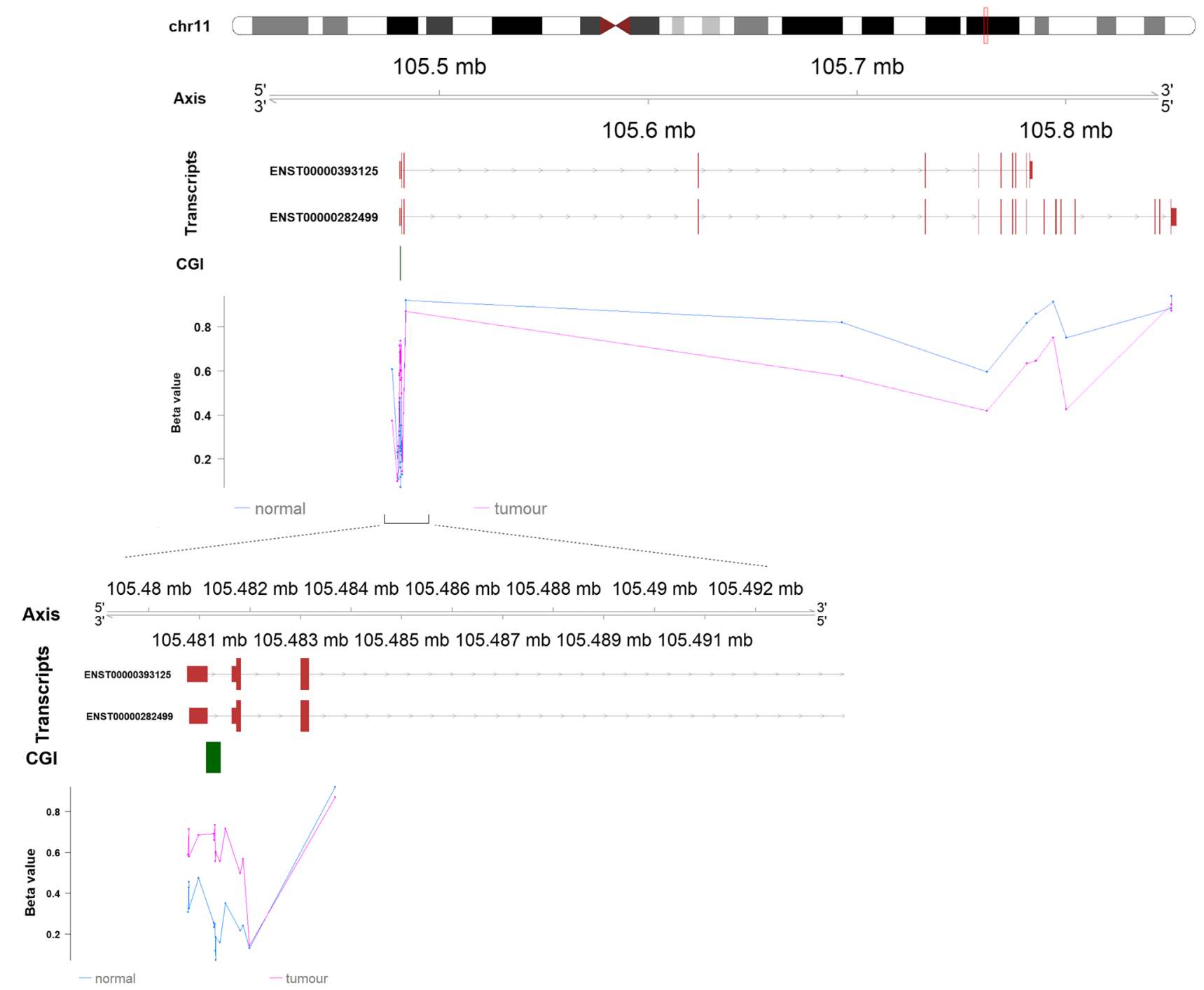

Fig. 2 Genomic organisation of GRIA4 including the localization of exons and CGI. Mean beta values resulting from the average of the samples (normal and tumour) of each probe mapping on the whole gene [1]. The zoom in focuses on the CGI located at the promoter region 


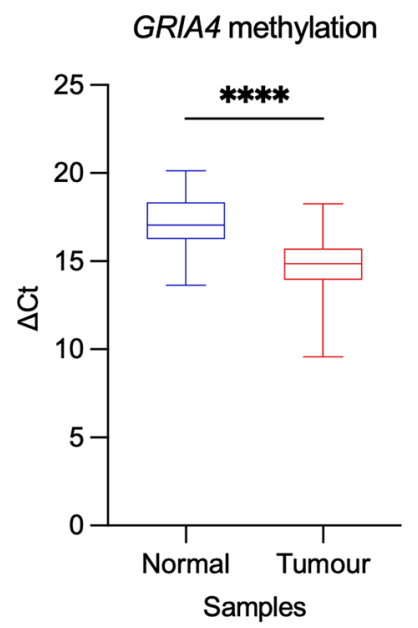

Fig. 3 GRIA4 methylation analysis. Box plot showing $\Delta \mathrm{Ct}$ values of GRIA4 methylation for normal and tumour tissues comparison. Asterisks indicate statistically significant differences $(* * * * p$ value $<0.0001)$

\section{Statistical analyses}

Statistical differences in the quantitative levels between sample groups were evaluated considering the average $\Delta \mathrm{Ct}$ for methylation/mRNA and the band intensity for protein evaluation. Statistics was calculated using Welch's $t$ test. When statistical significant differences were detected in the expression level between groups, we considered upregulation or downregulation.

\section{miRNA targets prediction}

We further evaluate post-transcriptional regulation by predicting miRNAs specific interactions with the two GRIA4 transcripts studied in this work. To achieve this aim we used bioinformatics tools: TargetScan (http://www.targetscan.org/ vert_72/), DIANA micro-T (http://diana.imis.athena-innov ation.gr/DianaTools/) and miRDB (mirdb.org).

\section{Results}

As mentioned above, we previously detected hypermethylation of a CGI located in the promoter region of GRIA4 [1] that may potentially affect the expression levels of the long and short isoforms. As shown in Fig. 2, normal cell DNA methylation pattern varies along GRIA4 gene, with lower methylation values in the promoter region than in the gene body, while, in tumour samples, higher DNA methylation levels in the promoter region and lower in the gene body have been detected compared to controls.

\section{GRIA4 methylation study}

GRIA4 methylation analysis of the investigation cohort confirmed a statistically significant hypermethylation (average $\Delta \Delta \mathrm{Ct}=-2.33, p$ value $<0.0001$ ) in tumoural samples compared to controls (Fig. 3), being $\Delta \mathrm{Ct}$ inversely correlated to methylation levels.

\section{mRNA expression study}

To evaluate whether hypermethylation in the promoter region of GRIA4 affects the expression of both alternative transcripts, a gene expression analysis has been performed by qRT-PCR. As observed in Fig. 4 the two transcript variants of GRIA4, analysed in the current work, are expressed in tumour and normal tissues. However, there exists a statistically significant reduction of both transcripts in CRC samples respect to normal tissues (Fig. 4A). We compared the expression levels between alternative transcripts in each tissue type and no significant differences have been detected (Fig. 4B).

\section{Protein expression study}

To study the protein expression, western blot analysis of GluR4 was performed in 10 paired samples analysed by qRT-PCR. Both isoforms of GluR4 were expressed in all samples, in agreement with their transcript expression (Fig. 5). A statistically significant reduction of GluR4 long was observed in CRC tissue, whereas the expression of the short isoform did not show any statistically significant difference between tumour and normal samples although a trend towards downregulation in the tumours can be observed (Fig. 5A and B). However, in contrast to the mRNA expression pattern of the two transcript variants, the short isoform of GluR4 displayed significant higher protein expression than the long isoform either in normal and tumoural tissues (Fig. 5C).

\section{miRNA targets analysis}

To explain the opposite expression results between mRNA and protein, we further investigate possible post-transcriptional regulators, such as miRNAs, using bioinformatics tools. Interestingly, using TargetScan four miRNAs, miR506-3p, miR-124-3p.1, miR-124-3p.2 and miR-137, highly conserved among vertebrates, with the strictest matching site types, i.e. branch length score 8 mer and 7 mer-A1, and high preferentially conserved targeting scores have been identified to target only the long GRIA4 transcript. Table 4 summarizes the characteristics of the selected miRNAs, including the Context++ score that considers 14 features such as stability, conservation, TA abundance among others, and 

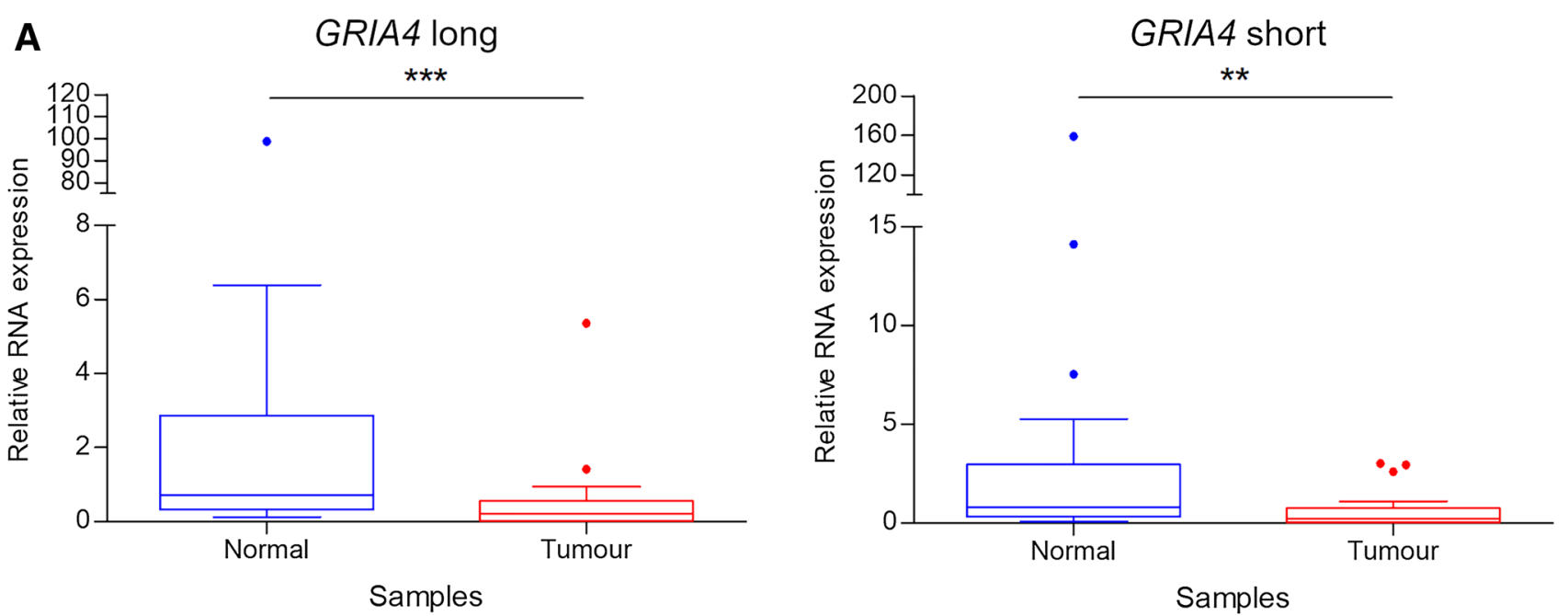

B

GRIA4 transcripts

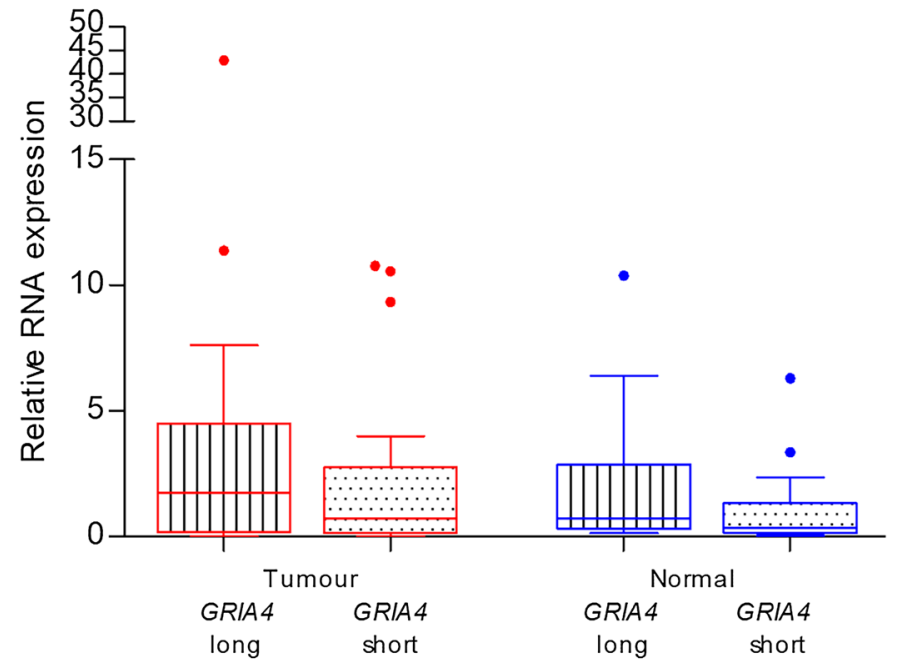

Fig. 4 GRIA4 gene expression analysis. A Box plot fold change values of GRIA4 long (on the left) and short (on the right) for normal and tumour tissues comparison. B Box plot fold change values of

$P_{\mathrm{CT}}$ parameter that estimates the site conservation due to miRNA target selectivity. These interactions have been also reported by other prediction tools; DIANA micro-T showing high confident miTG score 0.99 and 0.92 for miR-124 and miR-506 respectively and miRDB predicting interactions with target scores of 90 for miR-506 and miR-124, and 80 for miR-137. Instead, we did not identify any miRNAGRIA4 short interaction using the same parameters.

\section{Discussion}

Hypermethylation of GRIA4-associated promoter CGI is an early methylation event associated with GRIA4 downregulation at mRNA and protein level [1, 3, 20, 21]. In the present
GRIA4 variants comparison within tumours and normal colon tissues. Asterisks indicate statistically significant differences $(* * p$ value $<0.01, * * * p$ value $<0.001$ )

work, we firstly verified, and confirmed, the hypermethylated status of the aforementioned CGI associated to GRIA4 and further analysed its alternative transcripts and isoform expression levels in CRC paired tissue samples.

Several GRIA4 transcript variants and two protein isoforms were described but their expression in colon has not yet been tested. These glutamate receptors have a pivotal function in the nervous system where they are highly expressed. The majority of GRIA4 variants analyses are focused on the brain [22-25]. On the other hand, even the canonical isoform is lowly expressed in colon tissues, resulting in a possible underestimation of its involvement in cell intestinal biology (https://gtexportal.org/home/). However, an increasing number of evidences point out that genes involved in cellular crosstalk and in particular related to the 

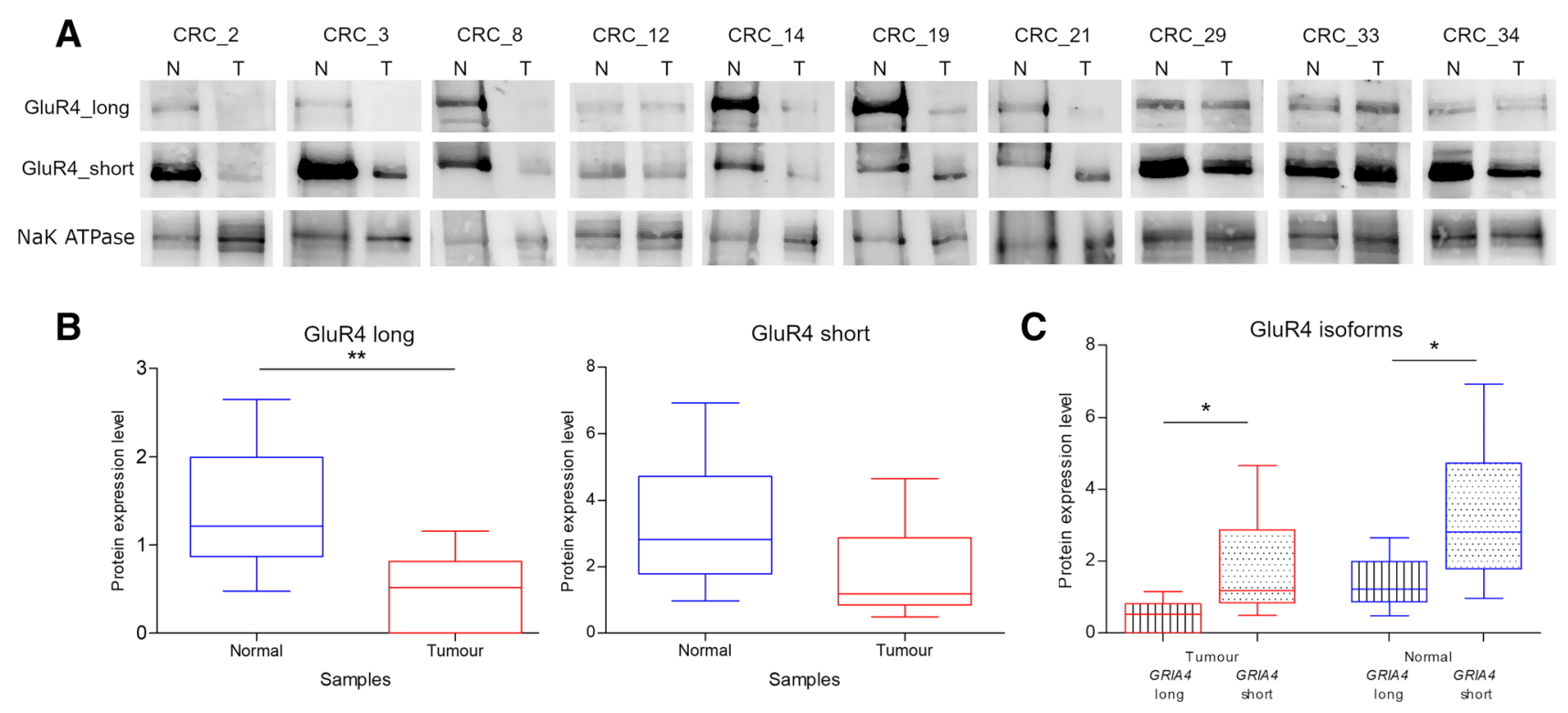

Fig. 5 GluR4 protein expression analysis. A Representative blots of GluR4 isoforms in ten CRC paired tissue samples. NaK ATPase was used as loading control. B Box plots of GluR4 long and short expres- sion in normal vs tumour samples. C Box plots of GluR4 isoforms within tumour and normal samples groups. Asterisks indicate statistically significant differences $\left(* p\right.$ value $<0.05,{ }^{*} p$ value $<0.01$ )

Table 4 GRIA4 long targeting miRNAs

\begin{tabular}{|c|c|c|c|c|}
\hline miRNA & $\begin{array}{c}\text { Predicted pairing of target region (top) and miRNA } \\
\text { (bottom) }\end{array}$ & $\begin{array}{l}\text { Site } \\
\text { type }\end{array}$ & $\begin{array}{l}\text { Context++ } \\
\text { score }\end{array}$ & $\boldsymbol{P}_{C T}$ \\
\hline hsa-miR-506-3p & 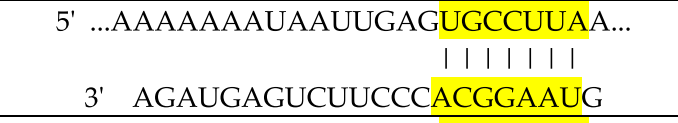 & 8 mer & -0.27 & 0.83 \\
\hline hsa-miR-124-3p.2 & 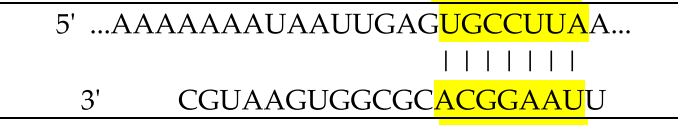 & 8 mer & -0.33 & 0.83 \\
\hline hsa-miR-124-3p.1 & 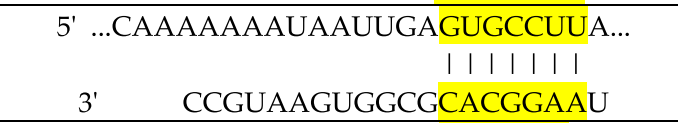 & 8 mer & -0.44 & 0.94 \\
\hline hsa-miR-137 & $\begin{array}{cc}5^{\prime} & \text {...AGGGAACAAUACAUUGCAAUAAU... } \\
& \text { । } \mid \text { । } \mid \text { । । } \\
\text { 3' } & \text { GAUGCGCAUAAGAAUUCGUUAUU } \\
\end{array}$ & 7mer-A1 & -0.17 & 0.87 \\
\hline
\end{tabular}

nervous system are epigenetically altered in CRC [1, 26]. We analysed the expression levels of two GRIA4 variants, long and short, that encode the canonical and the short isoforms. The novelty of our work resides on their detection for the first time using qPCR and Western blot in tumoural and normal colon tissues. The evident expression of both isoforms in a non-neuronal tissue opens a new research scenario to elucidate the glutamatergic signalling pathway in colon tissue.

As expected, the two variants were lower expressed in tumour tissue than in normal colon tissue, both at mRNA and protein levels.
The similar expression profile observed between alternative transcripts suggests that DNA hypermethylation regulate in the same way their transcription.

Opposite results were observed at protein level, where the short isoform resulted more expressed than the canonical isoform, both in normal and tumour tissues. This could be related, on one hand, to the lifetime of each isoform. In particular, the degradation mechanism of GluR4 is not well elucidated but previous evidence reported that caspases cleave GluR4 at the C-terminal domain contributing to selective proteolysis [27, 28]. This process could increase the susceptibility of GluR4 long canonical isoform to degradation but would not target the short one 
that lacks the C-terminal region. On the other hand, posttranscriptional regulation can be mediated by microRNAs (miRNAs). Four highly conserved miRNAs that target the long GRIA4 transcript have been identified using TargetScan. In contrast, no interaction between miRNAs and GRIA4 short transcript variant was predicted using the same parameters, suggesting a specific transcripts regulation and possibly resulting in the higher expression of the short isoform. The relationship between alternative transcripts and miRNA regulation is not well elucidated but previous works report variant-specific miRNA targeting [29-31].

Interestingly, although the unknown role of the short isoform, its constant expression in both tumoural and normal tissues led to expect that it may participate in cell function. It has been reported that the AMPA receptor assembly occurs in the endoplasmic reticulum through interactions between domains [15] and thus the extracellular domains of the short isoform could interact with the other glutamate receptor subunits. The extracellular region contains the signal peptide, also included in the short isoform that targets the protein to the membrane [15].

To conclude, our study is the first one to show the expression of different GRIA4 isoforms in CRC and normal colon tissue. As expected by the promoter hypermethylation found in GRIA4, both alternative transcripts and isoforms are downregulated in CRC.

The evident but even higher expression of the short isoform compared to the long in both tissue samples may suggest a role in the intestinal cell biology. Functional studies are necessary to confirm this hypothesis. The expression of the short isoform may lead to effects in downstream signalling pathways. Glutamate receptors' variants may modify the assembly and biophysical properties of the channels, affecting their main function as excitatory neurotransmitter receptors and their involvement in cellular homeostasis and in proliferation pathways such as the MAPK and PI3K/Akt, among others [32-35].

Our findings highlight the importance of post-transcriptional regulation mechanisms in GRIA4 alternative isoforms expression. The biological processes responsible of their different half-life must be addressed in future experimental assays.

Author contributions Conceptualization AFV-B, Pza. Data curation AFV-B, EL, LM, AP, PZ, MS and PZa. Formal analysis AFV-B and EL. Funding acquisition LZ and PZa. Investigation AFV-B, EL, LM, SO, AP, PZ, MS and PZa. Methodology AFV-B, EL, LM, SO, and PZa. Project administration PZa. Resources AR, FC, SD, LZ and PZa. Software AFV-B, EL. Supervision PZa. Visualization AFV-B, EL. Writing — original draft AFV-B. Writing—review and editing AFV-B, EL and PZa. All authors have read and agreed to the published version of the manuscript.
Funding This work was supported by grants from Fondazione Banco di Sardegna (2012), Fondo per la Ricerca Locale (ex 60\%), Università di Cagliari, POR FESR Sardegna (1C-177) to P.Za., Regione Autonoma della Sardegna (CRP-79303) to P.Za. and L.Z., Italian University Minister PON-AIM (F74I18000200001) to P.Za. financing A.F.V.B. research position, Fondazione di Sardegna (FdS) Salute pubblica Medicina preventiva e riabilitativa (Prot. U278.2021/AI.259.RP) to P.Za.

Data availability statement The data that support the findings of this study are available from the corresponding author, P.Za., upon reasonable request.

\section{Declarations}

Conflict of interests No potential competing interest was reported by the authors.

Ethical approval All the analysed biological samples were obtained with written informed consent from participants prior to inclusion in the study. The study protocol follows the ethical guidelines of the 1975 Declaration of Helsinki. The study was approved by the Independent Ethics Committee of the University Hospital of Cagliari (protocol \# PG/2021/1527).

Open Access This article is licensed under a Creative Commons Attribution 4.0 International License, which permits use, sharing, adaptation, distribution and reproduction in any medium or format, as long as you give appropriate credit to the original author(s) and the source, provide a link to the Creative Commons licence, and indicate if changes were made. The images or other third party material in this article are included in the article's Creative Commons licence, unless indicated otherwise in a credit line to the material. If material is not included in the article's Creative Commons licence and your intended use is not permitted by statutory regulation or exceeds the permitted use, you will need to obtain permission directly from the copyright holder. To view a copy of this licence, visit http://creativecommons.org/licenses/by/4.0/.

\section{References}

1. Fadda A, Gentilini D, Moi L, Barault L, Leoni VP, Sulas P, et al. Colorectal cancer early methylation alterations affect the crosstalk between cell and surrounding environment, tracing a biomarker signature specific for this tumor. Int J Cancer. 2018;143(4):90720. https://doi.org/10.1002/ijc.31380.

2. Vega-Benedetti AF, Loi E, Moi L, Blois S, Fadda A, Antonelli $\mathrm{M}$, et al. Clustered protocadherins methylation alterations in cancer. Clin Epigenet. 2019;11(1):100. https://doi.org/10.1186/ s13148-019-0695-0.

3. Vega-Benedetti AF, Loi E, Moi L, Orru S, Ziranu P, Pretta A, et al. Colorectal cancer early detection in stool samples tracing $\mathrm{CpG}$ islands methylation alterations affecting gene expression. Int J Mol Sci. 2020. https://doi.org/10.3390/ijms21124494.

4. Reddington JP, Sproul D, Meehan RR. DNA methylation reprogramming in cancer: does it act by re-configuring the binding landscape of Polycomb repressive complexes? BioEssays. 2014;36(2):134-40. https://doi.org/10.1002/bies.201300130.

5. Luo Y, Wong CJ, Kaz AM, Dzieciatkowski S, Carter KT, Morris SM, et al. Differences in DNA methylation signatures reveal multiple pathways of progression from adenoma to colorectal cancer. Gastroenterology. 2014;147(2):418-29.e8. https://doi.org/10. 1053/j.gastro.2014.04.039. 
6. Loi E, Moi L, Fadda A, Satta G, Zucca M, Sanna S, et al. Methylation alteration of SHANK1 as a predictive, diagnostic and prognostic biomarker for chronic lymphocytic leukemia. Oncotarget. 2019;10(48):4987-5002. https://doi.org/10.18632/oncotarget.27080.

7. Antonelli M, Fadda A, Loi E, Moi L, Zavattari C, Sulas P, et al. Integrated DNA methylation analysis identifies topographical and tumoral biomarkers in pilocytic astrocytomas. Oncotarget. 2018;9(17):13807-21. https://doi.org/10.18632/oncotarget.24480.

8. Klutstein M, Nejman D, Greenfield R, Cedar H. DNA methylation in cancer and aging. Can Res. 2016;76(12):3446-50. https://doi.org/10.1158/0008-5472.CAN-15-3278.

9. Feinberg AP, Ohlsson R, Henikoff S. The epigenetic progenitor origin of human cancer. Nat Rev Genet. 2006;7(1):21-33. https://doi.org/10.1038/nrg1748.

10. Kulis M, Heath S, Bibikova M, Queiros AC, Navarro A, Clot G, et al. Epigenomic analysis detects widespread gene-body DNA hypomethylation in chronic lymphocytic leukemia. Nat Genet. 2012;44(11):1236-42. https://doi.org/10.1038/ng.2443.

11. Mikeska T, Craig JM. DNA methylation biomarkers: cancer and beyond. Genes. 2014;5(3):821-64. https://doi.org/10.3390/ genes5030821.

12. Toiyama Y, Okugawa Y, Goel A. DNA methylation and microRNA biomarkers for noninvasive detection of gastric and colorectal cancer. Biochem Biophys Res Commun. 2014;455(12):43-57. https://doi.org/10.1016/j.bbrc.2014.08.001.

13. Acunzo M, Romano G, Wernicke D, Croce CM. MicroRNA and cancer-a brief overview. Adv Biol Regul. 2015;57:1-9. https:// doi.org/10.1016/j.jbior.2014.09.013.

14. Zhang M, Li Y, Wang H, Yu W, Lin S, Guo J. LncRNA SNHG5 affects cell proliferation, metastasis and migration of colorectal cancer through regulating miR-132-3p/CREB5. Cancer Biol Ther. 2019;20(4):524-36. https://doi.org/10.1080/15384047.2018.1537579.

15. Traynelis SF, Wollmuth LP, McBain CJ, Menniti FS, Vance $\mathrm{KM}$, Ogden KK, et al. Glutamate receptor ion channels: structure, regulation, and function. Pharmacol Rev. 2010;62(3):40596. https://doi.org/10.1124/pr.109.002451.

16. Martin S, Chamberlin A, Shinde DN, Hempel M, Strom TM, Schreiber A, et al. De Novo variants in GRIA4 lead to intellectual disability with or without seizures and gait abnormalities. Am J Hum Genet. 2017;101(6):1013-20. https://doi.org/ 10.1016/j.ajhg.2017.11.004.

17. Gerhard DS, Wagner L, Feingold EA, Shenmen CM, Grouse LH, Schuler G, et al. The status, quality, and expansion of the NIH full-length cDNA project: the Mammalian Gene Collection (MGC). Genome Res. 2004;14(10B):2121-7. https://doi.org/10.1101/gr.2596504.

18. Campan M, Weisenberger DJ, Trinh B, Laird PW. MethyLight and digital MethyLight. Methods Mol Biol. 2018;1708:497513. https://doi.org/10.1007/978-1-4939-7481-8_25.

19. Livak KJ, Schmittgen TD. Analysis of relative gene expression data using real-time quantitative PCR and the 2(-Delta Delta C(T)) Method. Methods. 2001;25(4):402-8. https://doi.org/10. 1006/meth.2001.1262.

20. Hauptman N, Jevsinek Skok D, Spasovska E, Bostjancic E, Glavac D. Genes CEP55, FOXD3, FOXF2, GNAO1, GRIA4, and KCNA5 as potential diagnostic biomarkers in colorectal cancer. BMC Med Genomics. 2019;12(1):54. https://doi.org/10.1186/ s12920-019-0501-z.

21. Barault L, Amatu A, Siravegna G, Ponzetti A, Moran S, Cassingena A, et al. Discovery of methylated circulating DNA biomarkers for comprehensive non-invasive monitoring of treatment response in metastatic colorectal cancer. Gut. 2018;67(11):1995-2005. https://doi.org/10.1136/ gutjnl-2016-313372.
22. Sommer B, Keinanen K, Verdoorn TA, Wisden W, Burnashev N, Herb A, et al. Flip and flop: a cell-specific functional switch in glutamate-operated channels of the CNS. Science. 1990;249(4976):1580-5. https://doi.org/10.1126/science.1699275.

23. Gallo V, Upson LM, Hayes WP, Vyklicky L Jr, Winters CA, Buonanno A. Molecular cloning and development analysis of a new glutamate receptor subunit isoform in cerebellum. J Neurosci. 1992;12(3):1010-23.

24. Kawahara Y, Ito K, Sun H, Ito M, Kanazawa I, Kwak S. GluR4c, an alternative splicing isoform of GluR4, is abundantly expressed in the adult human brain. Brain Res Mol Brain Res. 2004;127(12):150-5. https://doi.org/10.1016/j.molbrainres.2004.05.020.

25. Herbrechter R, Hube N, Buchholz R, Reiner A. Splicing and editing of ionotropic glutamate receptors: a comprehensive analysis based on human RNA-Seq data. Cell Mol Life Sci CMLS. 2021;78(14):5605-30. https://doi.org/10.1007/ s00018-021-03865-z.

26. Rademakers G, Massen M, Koch A, Draht MX, Buekers N, Wouters KAD, et al. Identification of DNA methylation markers for early detection of CRC indicates a role for nervous system-related genes in CRC. Clin Epigenet. 2021;13(1):80. https://doi.org/10. 1186/s13148-021-01067-9.

27. Chan SL, Griffin WS, Mattson MP. Evidence for caspase-mediated cleavage of AMPA receptor subunits in neuronal apoptosis and Alzheimer's disease. J Neurosci Res. 1999;57(3):315-23. https:// doi.org/10.1002/(SICI)1097-4547(19990801)57:3\%3c315::AIDJNR3\%3e3.0.CO;2-\#.

28. Meyer EL, Gahring LC, Rogers SW. Nicotine preconditioning antagonizes activity-dependent caspase proteolysis of a glutamate receptor. J Biol Chem. 2002;277(13):10869-75. https://doi.org/10. 1074/jbc.M106744200.

29. Duursma AM, Kedde M, Schrier M, le Sage C, Agami R. miR148 targets human DNMT3b protein coding region. RNA. 2008;14(5):872-7. https://doi.org/10.1261/rna.972008.

30. Passetti F, Ferreira CG, Costa FF. The impact of microRNAs and alternative splicing in pharmacogenomics. Pharmacogenomics J. 2009;9(1):1-13. https://doi.org/10.1038/tpj.2008.14.

31. Han S, Kim D, Shivakumar M, Lee YJ, Garg T, Miller JE, et al. The effects of alternative splicing on miRNA binding sites in bladder cancer. PLoS ONE. 2018;13(1): e0190708. https://doi.org/10. 1371/journal.pone.0190708.

32. Prickett TD, Samuels Y. Molecular pathways: dysregulated glutamatergic signaling pathways in cancer. Clin Cancer Res. 2012;18(16):4240-6. https://doi.org/10.1158/1078-0432. CCR-11-1217.

33. Vance KM, Hansen KB, Traynelis SF. GluN1 splice variant control of GluN1/GluN2D NMDA receptors. J Physiol. 2012;590(16):385775. https://doi.org/10.1113/jphysiol.2012.234062.

34. Hadzic M, Jack A, Wahle P. Ionotropic glutamate receptors: which ones, when, and where in the mammalian neocortex. J Comp Neurol. 2017;525(4):976-1033. https://doi.org/10.1002/cne.24103.

35. Liu H, Wang H, Peterson M, Zhang W, Hou G, Zhang ZW. N-terminal alternative splicing of GluN1 regulates the maturation of excitatory synapses and seizure susceptibility. Proc Natl Acad Sci USA. 2019;116(42):21207-12. https://doi.org/10.1073/pnas. 1905721116.

Publisher's Note Springer Nature remains neutral with regard to jurisdictional claims in published maps and institutional affiliations. 